\title{
Short-term outcomes in infants with mild neonatal encephalopathy: a retrospective, observational study
}

\author{
${\text { Yoshinori Aoki }{ }^{*} \text {, Tatsuo Kono }}^{2}$, Mikako Enokizono ${ }^{2}$ and Kaoru Okazaki ${ }^{1}$
}

\begin{abstract}
Background: Neonatal encephalopathy due to acute perinatal asphyxia is a major cause of perinatal brain damage. Moderate to severe neonatal encephalopathy is associated with high mortality and morbidity rates. However, the neurodevelopmental outcomes in neonates with mild neonatal encephalopathy are unclear. The primary aim of this single-center observational study was to assess the short-term outcomes in term neonates with mild neonatal encephalopathy due to perinatal asphyxia. A secondary aim was to identify predictors of poor prognosis by identifying the characteristics of these infants according to their short-term outcomes.

Methods: We retrospectively investigated all infants with perinatal asphyxia at Tokyo Metropolitan Children's Medical Center from January 2014 to December 2019. An abnormal short-term outcome was defined as any one of the following: seizures or abnormal electroencephalography, abnormal brain magnetic resonance imaging obtained within the first 4 weeks of life, and abnormal neurological examination findings at discharge.

Results: In total, 110 term infants with perinatal asphyxia during the study period were screened and 61 were diagnosed with mild neonatal encephalopathy. Eleven (18\%) of these infants had an abnormal short-term outcome. The median Thompson score at admission was significantly higher in infants with abnormal short-term outcomes than in those with normal short-term outcomes (5 [interquartile range, 4-5.5] vs. 2 [interquartile range, 1-3], $p<0.01$ ). Receiver operating characteristic curve analysis showed that a cutoff value of 4 had high sensitivity and specificity (90.9 and $83.0 \%$, respectively) for prediction of an abnormal short-term outcome.

Conclusions: $18 \%$ of infants with mild encephalopathy had an abnormal short-term outcome, such as abnormal brain magnetic resonance imaging findings. The Thompson score at admission may be a useful predictor of an abnormal short-term outcome in infants with mild neonatal encephalopathy.
\end{abstract}

Keywords: Mild neonatal encephalopathy, Perinatal asphyxia, Magnetic resonance imaging, Brain, Thompson score, Outcome

\footnotetext{
*Correspondence: yoaoki-tky@umin.ac.jp

'Department of Neonatology, Tokyo Metropolitan Children's Medical Center,

2-8-9 Musashidai, Fuchu, 183-8561 Tokyo, Japan

Full list of author information is available at the end of the article
}

(c) The Author(s). 2021 Open Access This article is licensed under a Creative Commons Attribution 4.0 International License, which permits use, sharing, adaptation, distribution and reproduction in any medium or format, as long as you give appropriate credit to the original author(s) and the source, provide a link to the Creative Commons licence, and indicate if changes were made. The images or other third party material in this article are included in the article's Creative Commons licence, unless indicated otherwise in a credit line to the material. If material is not included in the article's Creative Commons licence and your intended use is not permitted by statutory regulation or exceeds the permitted use, you will need to obtain permission directly from the copyright holder. To view a copy of this licence, visit http://creativecommons.org/licenses/by/4.0/ The Creative Commons Public Domain Dedication waiver (http://creativecommons.org/publicdomain/zero/1.0/) applies to the data made available in this article, unless otherwise stated in a credit line to the data. 


\section{Background}

Neonatal encephalopathy (NE, also known as hypoxicischemic encephalopathy) due to acute perinatal asphyxia is a major cause of perinatal brain damage [1-3]. NE has an incidence of 2 to 8 per 1,000 live births and is associated with high morbidity and mortality rates $[4,5]$. Several randomized controlled trials have demonstrated the effectiveness of therapeutic hypothermia in infants with moderate or severe NE [6-8]. As a result, therapeutic hypothermia was described as a standard treatment for moderate and severe NE at the 2010 International Consensus Conference on Cardiopulmonary Resuscitation and Emergency Cardiovascular Care Science with Treatment Recommendations and is now used in many countries $[9,10]$.

On the other hand, infants with mild NE have been considered to have a good prognosis $[11,12]$. Therefore, neuroprotective therapy such as therapeutic hypothermia is thought to be unnecessary for infants with mild NE. However, the neurological prognosis has been noted to be poor in some infants with mild NE [13-16]. Moreover, therapeutic hypothermia is often implemented for mild NE despite lack of sufficient evidence $[17,18]$.

In this study, we aimed to investigate the short-term outcomes in a single-center cohort of term neonates with mild NE. As a secondary aim, we sought to identify predictors of poor prognosis in these infants.

\section{Methods}

\section{Study design}

This single-center retrospective observational study assessed the short-term outcomes in term neonates with mild NE due to perinatal asphyxia at the Tokyo Metropolitan Children's Medical Center between January 2014 and December 2019. This institution's neonatal intensive care unit (NICU) is a tertiary center and provides medical care in the west of Tokyo, where about 30,000 infants are born annually. The study was approved by our institutional ethics committee. The need for informed consent was waived in view of the retrospective design of the study.

\section{Study population}

All infants born during the study period were screened to identify those who were admitted to the NICU within $5.5 \mathrm{~h}$ of birth, were born at $\geq 36$ weeks' gestation, had a birth weight $\geq 1800 \mathrm{~g}$, and showed evidence of perinatal asphyxia. Infants with major malformation or insufficient data were excluded. Newborns with perinatal asphyxia were identified by the same criteria as those used in a previous study of therapeutic hypothermia [7]: (1) $\mathrm{pH}<$ 7.0 or base deficit $\geq 16 \mathrm{mmol} / \mathrm{L}$ in a sample of umbilical cord blood or any blood during the first hour after birth; (2) an acute perinatal event with either a 10-min Apgar score $\leq 5$ or assisted ventilation initiated at birth and continued for at least $10 \mathrm{~min}$.

A standardized neurological examination was performed in newborns who met these criteria. The severity of NE was assessed using the modified Sarnat staging as in the National Institute of Child Health and Human Development (NICHD) therapeutic hypothermia trial $[7,11]$. Specifically, the severity of NE was classified based on the following 6 categories: level of consciousness, spontaneous activity, posture, tone, primitive reflexes (suck and Moro), and autonomic nervous system function (pupils, heart rate, or respiration). The parameters in each category were classified as normal, mild, moderate, or severe. Infants with a moderate or severe abnormality found in $\geq 3$ categories were classified as having moderate or severe NE, based on the number of moderate or severe abnormalities. Infants with an abnormality (of any severity) in $\geq 1$ category but no evidence of moderate or severe NE were classified as having mild NE. Infants with no abnormalities were classified as normal (without NE). We also evaluated the Thompson score on admission to the NICU. The Thompson score is a numeric scoring system that includes the following 9 neurological signs and vital parameters: tone, level of consciousness, fits (seizures), posture, Moro reflex, grasp reflex, suck reflex, fontanelle findings, and respiration. The total score ranges from 0 (normal) to 22 (severe) points [19].

Therapeutic hypothermia was performed for infants with moderate or severe NE without severe complications. Therapeutic hypothermia was administered in some infants with mild NE according to the discretion of the attending doctors.

\section{Outcomes}

Abnormal short-term outcomes were defined as any one of the following at discharge from the NICU based on their relation with neurodevelopmental impairment: seizures or abnormal findings on electroencephalography [20, 21], abnormal brain magnetic resonance imaging (MRI) findings within 4 weeks of age [13, 17, 22, 23], abnormal neurological examination findings at discharge from the NICU [24].

Electroencephalographic and MRI studies were performed when clinically indicated. MRI protocols consisted of conventional T1-weighted, T2-weighted, and diffusion-weighted sequences. MRI scans were reviewed by experienced pediatric radiologists.

\section{Statistical analysis}

Data are shown as the mean \pm standard deviation for normally distributed continuous variables, as the median and interquartile range (IQR) for other continuous variables, and as the number and percentage of the total 
number of infants for categorical variables. Statistical analyses were performed using SPSS Statistics version 26.0 (IBM Corp., Armonk, NY). Differences between the groups were evaluated using the Mann-Whitney $U$ test for continuous variables and Fisher's exact test for categorical variables. The ability of the Thompson score to predict the short-term outcomes was assessed using receiver operating characteristic (ROC) curve analysis. A $p$-value $<0.05$ was considered statistically significant.

\section{Results}

A total of 2883 infants were admitted to the NICU during the study period. Of these infants, 131 were identified to be term infants with perinatal asphyxia, 21 of which were excluded because of major malformations $(\mathrm{n}=19)$ or insufficient data $(\mathrm{n}=2)$. The remaining 110 eligible infants were categorized according to severity of NE (Fig. 1). Of these, 61 newborns were diagnosed to have mild NE and formed the study population. Five infants were diagnosed to be normal (without NE), 31 to have moderate NE, and 13 to have severe NE; the characteristics of these infants and their treatment course are shown in Additional file 1 Therapeutic hypothermia was provided for 12 infants $(20 \%)$ with mild NE according to the discretion of the attending doctors. The characteristics of infants who were treated with therapeutic hypothermia are shown in Additional File 2 At our facility, therapeutic hypothermia was more likely to be provided to infants who had a worse Apgar score at $5 \mathrm{~min}$, had worse blood gas results, or required tracheal intubation and vasopressor. MRI studies were performed in 40 infants with mild NE as clinically indicated.

Table 1 compares the infants with mild NE according to whether their short-term outcomes were normal or abnormal. Eleven infants (18\%) had some abnormalities at the time of discharge; 10 had abnormal brain MRI findings and 1 had abnormal findings on brain MRI, abnormalities on neurological examination at discharge, seizures, and abnormal background activity on electroencephalography. The abnormal brain MRI findings consisted of lesions in the basal ganglia and/or thalami in 6 infants, lesions in the white matter in 3 infants, lesions in the basal ganglia, thalami, and white matter bilaterally in 1 infant, and lesions in the cerebral cortex, white matter, basal ganglia, and thalami in the remaining infant. Further information on these infants is provided in Additional File 3. Some examples of abnormal MRI findings are shown in Additional File 4. There was no difference between the groups in maternal characteristics or complications, need for resuscitation in the delivery room, Apgar scores at 1 and $5 \mathrm{~min}$, or the lowest blood gas $\mathrm{pH}$ value obtained in the first $6 \mathrm{~h}$ after birth (Table 1). The

131 infants screened:

- Term infants with perinatal asphyxia

- Admission within $5.5 \mathrm{~h}$ after birth

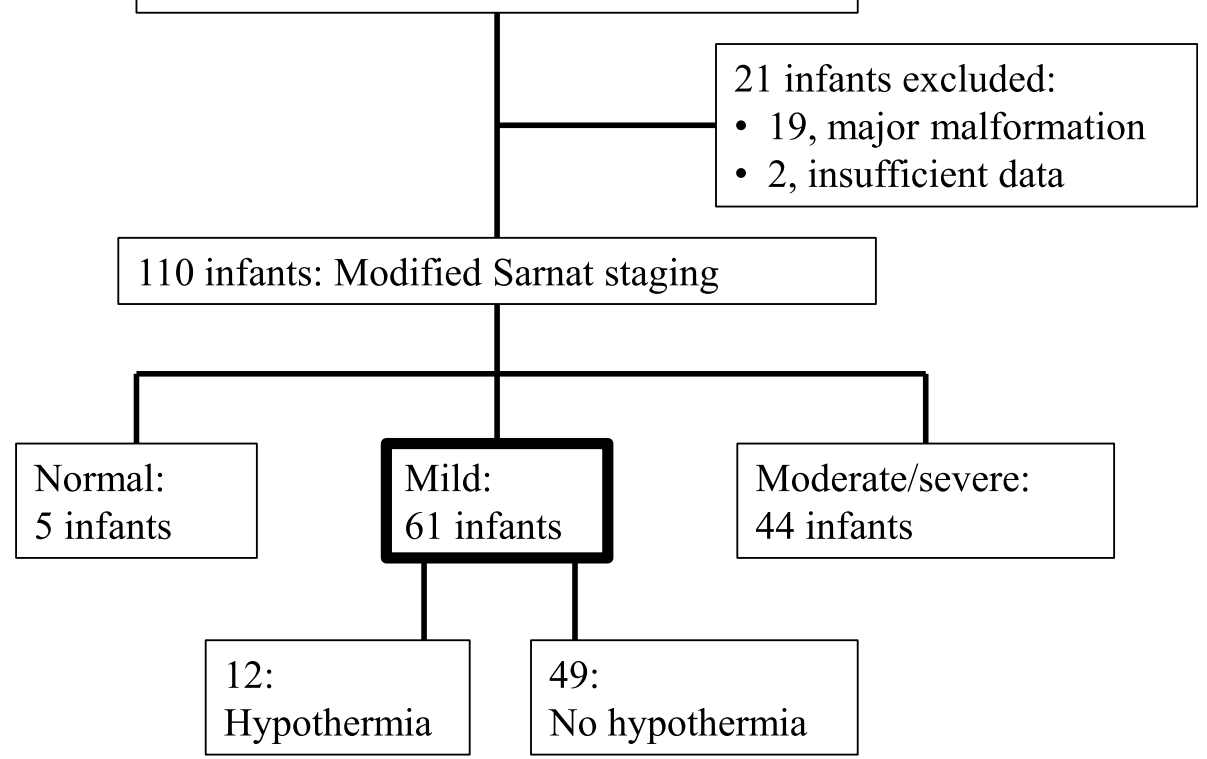

Fig. 1 Enrollment, classification, and treatment of the study infants. Infants who met the inclusion criteria and none of the exclusion criteria. Perinatal asphyxia was defined as one or more of the following: 10 min Apgar score $\leq 5$, resuscitation $\geq 10$ min, blood gas pH $<7.0$, and blood gas base deficit $\geq 16$. One patient with Sarnat stage 2 neonatal encephalopathy did not receive therapeutic hypothermia due to severe bleeding 
Table 1 Comparison between infants with mild NE according to whether short-term outcomes were normal or abnormal

\begin{tabular}{|c|c|c|c|}
\hline & Abnormal & Normal & $p$-value \\
\hline Infants, n (\%) & 11 & 50 & \\
\hline Male sex, n (\%) & $6(55)$ & $32(64)$ & 0.56 \\
\hline Gestational age (weeks), median (IQR) & $39(39-39)$ & $39(37.5-40)$ & 0.93 \\
\hline Birth weight $(\mathrm{g})$, mean $\pm \mathrm{SD}$ & $2848 \pm 378$ & $2934 \pm 529$ & 0.48 \\
\hline \multicolumn{4}{|l|}{ Mode of delivery } \\
\hline Cesarean delivery, n (\%) & $4(36)$ & $22(44)$ & 0.64 \\
\hline Vacuum extraction, n (\%) & $3(27)$ & $9(18)$ & 0.48 \\
\hline Natural, n (\%) & $4(36)$ & $19(38)$ & 0.89 \\
\hline Non-reassuring fetal status, n (\%) & $10(91)$ & $28(56)$ & 0.09 \\
\hline Placental abruption, n (\%) & $3(27)$ & $11(22)$ & 0.59 \\
\hline Outborn delivery, n (\%) & $7(64)$ & $43(86)$ & 0.09 \\
\hline Apgar score at 1 min, median (IQR) & $2(1-2.5)$ & $2(1-3)$ & 0.14 \\
\hline Apgar score at 5 min, median (IQR) & $5(3-5.5)$ & $5(4-6)$ & 0.38 \\
\hline Intubation (in delivery room), n (\%) & $6(55)$ & $32(64)$ & 0.56 \\
\hline Cardiac compression, n (\%) & $2(18)$ & $2(4)$ & 0.09 \\
\hline$C P R \geq 10$ min, $n(\%)$ & $9(82)$ & $41(82)$ & 1.0 \\
\hline Blood gas pH, median (IQR) & $6.97(6.89-7.11)$ & $7.03(6.92-7.15)$ & 0.69 \\
\hline Blood gas base deficit, median (IQR) & $17(15-21)$ & $11(7.8-19)$ & 0.04 \\
\hline Thompson score, median (IQR) & $5(4-5.5)$ & $2(1-3)$ & $<0.01$ \\
\hline Vasopressor use, n (\%) & $2(18)$ & $15(30)$ & 0.43 \\
\hline Therapeutic hypothermia, n (\%) & $1(9)$ & $11(22)$ & 0.33 \\
\hline
\end{tabular}

Blood gas pH: lowest $\mathrm{pH}$ in either umbilical cord blood or infant blood recorded within the first $6 \mathrm{~h}$ of birth. Blood gas base deficit: highest base deficit in either umbilical cord blood or infant blood recorded within the first $6 \mathrm{~h}$ of birth. CPR cardiopulmonary resuscitation; IQR interquartile range; SD standard deviation

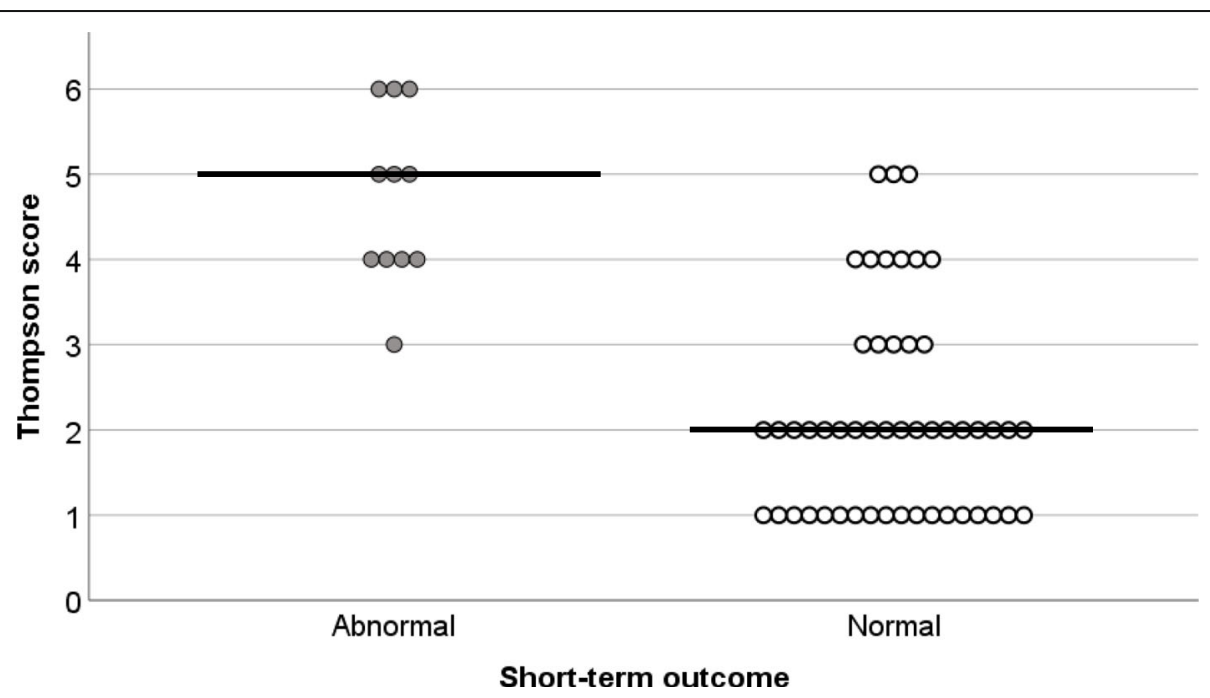

Fig. 2 Thompson scores in infants with and without abnormal short-term outcomes. The horizontal line shows the median in the scatterplot. The scores were significantly higher in infants with abnormal short-term outcomes than in those with normal short-term outcomes $(p<0.01)$ 


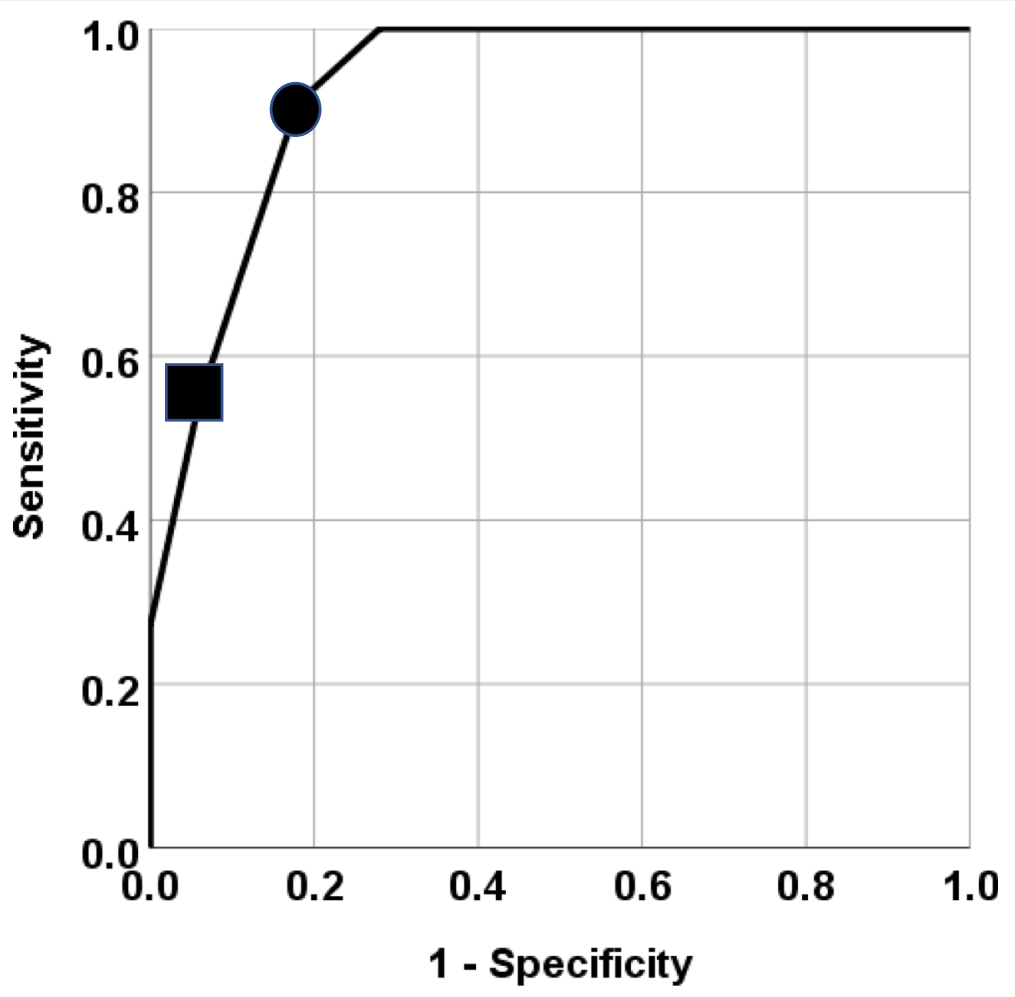

Fig. 3 Receiver operating characteristic curve analysis of Thompson score as a predictor of short-term outcome. The area under the curve was 0.93 (95\% confidence interval 0.86-0.99). The black circle and square indicate cutoff points of 4 and 5, respectively. When the cutoff value was 4 , the sensitivity and specificity were $90.9 \%$ and $83.0 \%$, respectively, and the positive and negative predictive values were $52.6 \%$ and $97.6 \%$

highest blood gas base deficit recorded within the first $6 \mathrm{~h}$ was significantly higher in the infants with abnormal short-term outcomes (median 17 [IQR 5-21] vs. 11 [IQR 7.8-19], $p=0.04$ ). Furthermore, the Thompson scores at admission were significantly higher in infants with abnormal short-term outcomes than in those with normal short-term outcomes (median 5 [IQR 4-5.5] vs. 2 [IQR 1-3], $p<0.01$; Fig. 2). ROC curve analysis of the ability of the Thompson score at admission to predict an abnormal short-term outcome revealed an area under the curve of 0.93 (95\% confidence interval, 0.86-0.99; Fig. 3). When the cutoff value was 4 , the sensitivity and specificity were 90.9 and $83.0 \%$, respectively, with

Table 2 Sensitivity, specificity, PPV, and NPV of the Thompson score in prediction of abnormal short-term outcomes

\begin{tabular}{lllll}
\hline Thompson score & Sensitivity & Specificity & PPV & NPV \\
\hline 2 & $100 \%$ & $36 \%$ & $25 \%$ & $100 \%$ \\
3 & $100 \%$ & $73 \%$ & $44 \%$ & $100 \%$ \\
$\mathbf{4}$ & $\mathbf{9 0 . 9 0 \%}$ & $\mathbf{8 3} \%$ & $\mathbf{5 2 . 6 0 \%}$ & $\mathbf{9 7 . 6 0 \%}$ \\
5 & $54.50 \%$ & $94 \%$ & $66.70 \%$ & $90.40 \%$ \\
6 & $27.30 \%$ & $100 \%$ & $100 \%$ & $86.20 \%$ \\
\hline
\end{tabular}

NPV negative predictive value; PPV positive predictive value positive and negative predictive values of 52.6 and $97.6 \%$ (Table 2). We also assessed the effects of therapeutic hypothermia. One $(8 \%)$ of the 12 infants with an abnormal short-term outcome had received therapeutic hypothermia. In contrast, 11 (22\%) of the 49 infants who did not have any abnormal neurological findings at discharge had received therapeutic hypothermia (22\%). However, there was no significant difference $(p=0.33)$.

A Thompson score of 4 (shown in bold) had high sensitivity and specificity ( 90.9 and $83.0 \%$, respectively) with positive and negative predictive values of 52.6 and $97.6 \%$.

\section{Discussion}

In this study, we found that $18 \%$ of infants with mild NE had abnormal short-term outcomes such as abnormal brain MRI findings, abnormal neurological examination findings at discharge, or seizures. The Thompson score at admission may be useful for prediction of abnormal short-term outcomes in infants with mild NE.

Unlike moderate or severe cases, infants with mild NE have been considered to have a good prognosis $[11,12]$. However, accumulating evidence suggests that neonates with mild NE are also at risk for neurodevelopmental disorders [13-16]. One reason for 
these inconsistent reports may be a difference in timing of evaluation, in that the earlier studies defined mild NE by serial neurological examination during the first week after birth whereas the therapeutic hypothermia trials defined the severity of NE based on evaluation within $6 \mathrm{~h}$ of birth [25]. Moreover, the timing and methods used to assess the prognosis varied in the earlier studies. In the present study, we found that a considerable number of infants with mild NE had abnormal short-term outcomes, which is consistent with previous studies. Most of the infants with abnormal short-term outcomes in this study had abnormal brain MRI findings; furthermore, there may have been infants with poor prognosis who went undetected because brain MRI was not performed in all cases. Although we did not assess neurodevelopmental outcomes at older ages, brain MRI abnormalities obtained within 4 weeks after birth are reported to be associated with neurodevelopmental impairments [22, 23]. In addition, we must consider not only problems that occur in early childhood but also those that arise in school-aged and adolescent children. van Kooij et al. reported that MRI abnormalities found in the neonatal period are also related to intelligence quotient (IQ) scores obtained in school-aged children and in children with special educational needs, and that even among infants with normal or mild lesions on neonatal MRI, 23.1\% (3/13) had an IQ score $\leq 85$ [26]. Furthermore, neuropsychological problems, such as poor attention/executive function, poor memory performance, and behavioral difficulties, have been identified in studies that have followed children with NE through to school age [27]. The long-term neuropsychological outcome of mild $\mathrm{NE}$ is controversial; some papers report that even mild NE can cause psychological problems $[28,29]$ while others report no concern if they are not severe [30]. Although the long-term prognosis of mild NE is not fully understood, we should be aware that the risk of poor neurological prognosis in children with $\mathrm{NE}$ of mild severity is not negligible. Therefore, it is important to continue to follow up infants with mild NE in the long term and accumulate data on their long-term outcomes.

Although the Sarnat score is the method most widely used to test for NE, the Thompson score at admission may also be a useful predictor of the short-term outcome in infants with mild NE. Introduced by Sarnat et al. in 1976, the Sarnat score requires evaluation of many items and is somewhat complicated to use [11]. The Thompson score was originally introduced as a simple and effective scoring system for predicting neurodevelopmental outcomes in neonates with hypoxicischemic encephalopathy before the era of therapeutic hypothermia. It is a numeric scoring system that requires no equipment or specific training to use. Scores $\geq$ 15 have been associated with cerebral palsy or severe developmental retardation [19]. Another study reported that the median Thompson score was 4 in mild to moderate encephalopathy and 9 in severe encephalopathy, which is consistent with our data for mild encephalopathy [31]. The Thompson score also has a high predictive value for outcomes in infants treated with therapeutic hypothermia [32]. Although we found that a Thompson score of 4 was a highly sensitive and highly specific predictor of an abnormal short-term outcome, the value was lower than that used by earlier researchers. Compared with previous studies of the predictive ability of the Thompson score $[19,32]$, we set a milder definition of abnormal outcomes. Therefore, it is possible that our cutoff score was lower than that in previous studies. A recent prospective study by Chalak et al. found that the total Sarnat score recorded in the first $6 \mathrm{~h}$ after birth can predict disability at $18-22$ months in infants with mild NE [33]. We propose inclusion of this simple scoring system, the Thompson score, into the prognostic assessment of mild NE, which is often treated in institutions without a neonatal neurological specialist.

We could not reach a conclusion regarding the effectiveness of therapeutic hypothermia for mild NE. While there are some papers suggesting that therapeutic hypothermia is effective in mild NE [34, 35], a recent meta-analysis could not confirm its effectiveness [36]. Although therapeutic hypothermia is often already provided for infants with mild NE, prospective trials are needed to confirm its efficacy in these infants. Our present findings suggest that poor prognosis is unlikely in children with milder NE who have a lower Thompson score, such as 1 or 2 , but that it is necessary to screen high-risk infants with mild NE in the trials. We hope that our findings will be useful in future research.

The limitations of this study include its retrospective design and lack of long-term follow-up in most cases. However, some infants had brain MRI abnormalities at discharge, which is associated with poor long-term prognosis. Therefore, we assume that mild encephalopathy does not always have a good prognosis.

\section{Conclusions}

We found that the neurological prognosis can be poor even in mild NE. The Thompson score at admission may be useful for prediction of abnormal short-term outcomes in infants with mild NE. Our findings may be helpful for selection of high-risk infants for enrolment in future trials of neuroprotective therapy.

\section{Abbreviations}

CPR: Cardiopulmonary resuscitation; IQ: Intelligence quotient:

IQR: Interquartile range; MRI: Magnetic resonance imaging; NE: Neonatal 
encephalopathy; NICU: Neonatal intensive care unit; NPV: Negative predictive value; PPV: Positive predictive value; ROC: Receiver operating characteristic

\section{Supplementary Information}

The online version contains supplementary material available at https://doi. org/10.1186/s12887-021-02688-y.

Additional file 1. Maternal and neonatal characteristics and short-term outcomes in infants. This file shows maternal and neonatal characteristics and short-term outcomes of all screened infants by severity.

Additional file 2. Comparison among infants with mild NE according to whether therapeutic hypothermia was provided or not. This file shows maternal and neonatal characteristics of infants with mild NE according to whether therapeutic hypothermia was provided or not.

Additional file 3. Details of infants with abnormal short-term outcomes This file shows detailed data for infants with mild neonatal encephalopathy who had an abnormal short-term outcome.

Additional file 4. Examples of abnormal MRI findings. A. Axial $T_{1}$ weighted sequence at 6 days of age showing a focal high signal intensity lesion of the white matter (Patient No. 2). B. Axial $T_{1}$-weighted sequence at 2 days of age showing bilateral high signal intensity lesions in the globus pallidus and subthalamic nuclei (Patient No. 5). C. Axial $T_{1}$ weighted sequence at 25 days of age showing bilateral high signal intensity changes and atrophy in the basal ganglia and thalamus as well as multicystic encephalomalacia in the greater part of the bilateral cerebral hemispheres (Patient No. 8)

\section{Acknowledgements}

We thank the parents of the infants included in this study for allowing their children to participate in this research. We also thank all the investigators who were involved in the study.

\section{Authors' contributions}

Y.A. designed the study, analyzed the data, drafted the initial manuscript, and was responsible for the final editing of the manuscript. T.A. and E.M. reviewed the MRI studies and reviewed the manuscript. K.O. supervised the study and reviewed and revised the manuscript. All authors approved the final manuscript.

\section{Funding}

This work was supported by JSPS KAKENHI grant number JP20K16875.

\section{Availability of data and materials}

The datasets used and analyzed during the current study are available from the corresponding author on reasonable request.

\section{Declarations}

\section{Ethics approval and consent to participate}

The study was approved by the Ethics Committee on Human Research at Tokyo Metropolitan Children's Medical Center (Approval 2020b-94). All procedures performed in the study were in accordance with national ethical guidelines for medical and health research involving human subjects and with the 1964 Helsinki declaration as well as its later amendments. Due to the retrospective nature of this study the need for informed consent was waived by the Ethics Committee on Human Research at Tokyo Metropolitan Children's Medical Center.

\section{Consent for publication}

Not applicable.

\section{Conflict of interest}

The authors declare that they have no competing interests.

\section{Author details}

'Department of Neonatology, Tokyo Metropolitan Children's Medical Center, 2-8-9 Musashidai, Fuchu, 183-8561 Tokyo, Japan. ²Department of Radiology, Tokyo Metropolitan Children's Medical Center, Tokyo, Japan.
Received: 15 December 2020 Accepted: 19 April 2021

Published online: 07 May 2021

\section{References}

1. Ferriero DM. Neonatal brain injury. N Engl J Med. 2004;351(19):1985-95.

2. Volpe JJ. Neonatal encephalopathy: an inadequate term for hypoxicischemic encephalopathy. Ann Neurol. 2012;72:156-66.

3. Douglas-Escobar M, Weiss MD. Hypoxic-ischemic encephalopathy: a review for the clinician. JAMA Pediatr. 2015;169:397-403.

4. Pierrat V, Haouari N, Liska A, Thomas D, Subtil D, Truffert P, Groupe d'Etudes en Epidemiologie $P$. Prevalence, causes, and outcome at 2 years of age of newborn encephalopathy: population based study. Arch Dis Child Fetal Neonatal Ed. 2005:90(3):F257-61.

5. Lee ACC, Kozuki N, Blencowe H, Vos T, Bahalim A, Darmstadt GL, Niermeyer S, Ellis M, Robertson NJ, Cousens S et al. Intrapartum-related neonatal encephalopathy incidence and impairment at regional and global levels for 2010 with trends from 1990. Pediatr Res. 2013;74 Suppl 1:50-72.

6. Gluckman PD, Wyatt JS, Azzopardi D, Ballard R, Edwards AD, Ferriero DM, Polin RA, Robertson CM, Thoresen M, Whitelaw A et al. Selective head cooling with mild systemic hypothermia after neonatal encephalopathy: multicentre randomised trial. Lancet. 2005;365(9460):663-70.

7. Shankaran S, Laptook AR, Ehrenkranz RA, Tyson JE, McDonald SA, Donovan EF, Fanaroff AA, Poole WK, Wright LL, Higgins RD et al. Whole-body hypothermia for neonates with hypoxic-ischemic encephalopathy. N Engl J Med. 2005;353(15):1574-84.

8. Azzopardi DV, Strohm B, Edwards AD, Dyet L, Halliday HL, Juszczak E, Kapellou O, Levene M, Marlow N, Porter E et al. Moderate hypothermia to treat perinatal asphyxial encephalopathy. N Engl J Med. 2009;361(14):1349-58.

9. Nolan JP, Hazinski MF, Billi JE, Boettiger BW, Bossaert L, de Caen AR, Deakin CD, Drajer S, Eigel B, Hickey RW et al. Part 1: Executive summary: 2010 International Consensus on Cardiopulmonary Resuscitation and Emergency Cardiovascular Care Science With Treatment Recommendations. Resuscitation. 2010;81 Suppl 1:e1-25.

10. Jacobs SE, Berg M, Hunt R, Tarnow-Mordi WO, Inder TE, Davis PG. Cooling for newborns with hypoxic ischaemic encephalopathy. Cochrane Database Syst Rev. 2013;2013(1):Cd003311.

11. Sarnat HB, Sarnat MS. Neonatal encephalopathy following fetal distress. A clinical and electroencephalographic study. Arch Neurol. 1976;33(10):696-705.

12. Robertson CM, Finer NN, Grace MG. School performance of survivors of neonatal encephalopathy associated with birth asphyxia at term. J Pediatr. 1989:114(5):753-60.

13. DuPont TL, Chalak LF, Morriss MC, Burchfield PJ, Christie L, Sanchez PJ. Short-term outcomes of newborns with perinatal acidemia who are not eligible for systemic hypothermia therapy. J Pediatr. 2013;162(1):35-41.

14. Murray DM, O'Connor CM, Ryan CA, Korotchikova I, Boylan GB. Early EEG Grade and Outcome at 5 Years After Mild Neonatal Hypoxic Ischemic Encephalopathy. Pediatrics. 2016;138(4):doi:10.1542.

15. Chalak LF, Nguyen KA, Prempunpong C, Heyne R, Thayyil S, Shankaran S, Laptook AR, Rollins N, Pappas A, Koclas L et al. Prospective research in infants with mild encephalopathy identified in the first six hours of life: neurodevelopmental outcomes at 18-22 months. Pediatr Res. 2018;84(6): 861-8.

16. Conway JM, Walsh BH, Boylan GB, Murray DM. Mild hypoxic ischaemic encephalopathy and long term neurodevelopmental outcome - A systematic review. Early Hum Dev. 2018;120:80-7.

17. Massaro AN, Murthy K, Zaniletti I, Cook N, DiGeronimo R, Dizon M, Hamrick SE, McKay VJ, Natarajan G, Rao R et al. Short-term outcomes after perinatal hypoxic ischemic encephalopathy: a report from the Children's Hospitals Neonatal Consortium HIE focus group. J Perinatol. 2015;35(4):290-6.

18. Oliveira V, Singhvi DP, Montaldo P, Lally PJ, Mendoza J, Manerkar S, Shankaran S, Thayyil S. Therapeutic hypothermia in mild neonatal encephalopathy: a national survey of practice in the UK. Arch Dis Child Fetal Neonatal Ed. 2018;103(4):F388-90.

19. Thompson CM, Puterman AS, Linley LL, Hann FM, van der Elst CW, Molteno $C D$, Malan AF. The value of a scoring system for hypoxic ischaemic encephalopathy in predicting neurodevelopmental outcome. Acta Paediatr. 1997:86(7):757-61.

20. Murray DM, Boylan GB, Ryan CA, Connolly S. Early EEG findings in hypoxic ischemic encephalopathy predict outcomes at 2 years. Pediatrics. 2009; 124(3):e459-67. 
21. Merchant N, Azzopardi D. Early predictors of outcome in infants treated with hypothermia for hypoxic-ischaemic encephalopathy. Dev Med Child Neurol. 2015;57 Suppl 3:8-16.

22. Rutherford M, Ramenghi LA, Edwards AD, Brocklehurst P, Halliday H, Levene M, Strohm B, Thoresen M, Whitelaw A, Azzopardi D. Assessment of brain tissue injury after moderate hypothermia in neonates with hypoxicischaemic encephalopathy: a nested substudy of a randomised controlled trial. The Lancet Neurology. 2010;9(1):39-45.

23. Shankaran S, McDonald SA, Laptook AR, Hintz SR, Barnes PD, Das A, Pappas A, Higgins RD. Eunice Kennedy Shriver National Institute of Child H, Human Development Neonatal Research N: Neonatal Magnetic Resonance Imaging Pattern of Brain Injury as a Biomarker of Childhood Outcomes following a Trial of Hypothermia for Neonatal Hypoxic-Ischemic Encephalopathy. J Pediatr. 2015;167(5):987-93.

24. Murray DM, Bala P, O'Connor CM, Ryan CA, Connolly S, Boylan GB. The predictive value of early neurological examination in neonatal hypoxicischaemic encephalopathy and neurodevelopmental outcome at 24 months. Dev Med Child Neurol. 2010;52(2):e55-9.

25. Chalak L, Latremouille S, Mir I, Sanchez PJ, Sant'Anna G. A review of the conundrum of mild hypoxic-ischemic encephalopathy: Current challenges and moving forward. Early Hum Dev. 2018;120:88-94.

26. van Kooij BJ, van Handel M, Nievelstein RA, Groenendaal F, Jongmans MJ, de Vries LS. Serial MRI and neurodevelopmental outcome in 9- to 10-yearold children with neonatal encephalopathy. J Pediatr. 2010;157(2):221-7.

27. de Vries LS, Jongmans MJ. Long-term outcome after neonatal hypoxicischaemic encephalopathy. Arch Dis Child Fetal Neonatal Ed. 2010;95(3): F220-4.

28. van Handel M, Swaab H, de Vries LS, Jongmans MJ. Behavioral outcome in children with a history of neonatal encephalopathy following perinata asphyxia. J Pediatr Psychol. 2010;35(3):286-95.

29. van Handel M, de Sonneville L, de Vries LS, Jongmans MJ, Swaab H. Specific memory impairment following neonatal encephalopathy in term-born children. Dev Neuropsychol. 2012;37(1):30-50.

30. Marlow N, Rose AS, Rands CE, Draper ES. Neuropsychological and educational problems at school age associated with neonatal encephalopathy. Arch Dis Child Fetal Neonatal Ed. 2005;90(5):F380-7.

31. Negro S, Benders M, Tataranno ML, Coviello C, de Vries LS, van Bel F, Groenendaal F, Longini M, Proietti F, Belvisi E et al. Early Prediction of Hypoxic-Ischemic Brain Injury by a New Panel of Biomarkers in a Population of Term Newborns. Oxid Med Cell Longev. 2018;2018:7608108.

32. Thorsen P, Jansen-van der Weide MC, Groenendaal F, Onland W, van Straaten HL, Zonnenberg I, Vermeulen JR, Dijk PH, Dudink J, Rijken M et al. The Thompson Encephalopathy Score and Short-Term Outcomes in Asphyxiated Newborns Treated With Therapeutic Hypothermia. Pediatr Neurol. 2016;60:49-53.

33. Chalak LF, Adams-Huet B, Sant'Anna G. A Total Sarnat Score in Mild Hypoxic-ischemic Encephalopathy Can Detect Infants at Higher Risk of Disability. J Pediatr. 2019;214:217-21.

34. Montaldo P, Lally PJ, Oliveira V, Swamy R, Mendoza J, Atreja G, Kariholu U, Shivamurthappa V, Liow N, Teiserskas J et al. Therapeutic hypothermia initiated within 6 hours of birth is associated with reduced brain injury on MR biomarkers in mild hypoxic-ischaemic encephalopathy: a nonrandomised cohort study. Arch Dis Child Fetal Neonatal Ed. 2019;104(5): F515-20.

35. Goswami IR, Whyte H, Wintermark P, Mohammad K, Shivananda S, Louis D, Yoon EW, Shah PS. Characteristics and short-term outcomes of neonates with mild hypoxic-ischemic encephalopathy treated with hypothermia. $J$ Perinatol. 2020;40(2):275-83.

36. Kariholu U, Montaldo P, Markati T, Lally PJ, Pryce R, Teiserskas J, Liow N, Oliveira V, Soe A, Shankaran $\mathrm{S}$ et al. Therapeutic hypothermia for mild neonatal encephalopathy: a systematic review and meta-analysis. Arch Dis Child Fetal Neonatal Ed. 2020;105(2):225-28.

\section{Publisher's Note}

Springer Nature remains neutral with regard to jurisdictional claims in published maps and institutional affiliations.

\section{Ready to submit your research? Choose BMC and benefit from:}

- fast, convenient online submission

- thorough peer review by experienced researchers in your field

- rapid publication on acceptance

- support for research data, including large and complex data types

- gold Open Access which fosters wider collaboration and increased citations

- maximum visibility for your research: over $100 \mathrm{M}$ website views per year

At BMC, research is always in progress.

Learn more biomedcentral.com/submissions 